\title{
A Socially-Just Internet: The Digital Divide, Cybercultural Agency, and Human Capabilities
}

\author{
David Toews, University of Windsor
}

\begin{abstract}
This article argues that while modes of scholarship stressing structural insights into the digital divide and ethnographic insights into online communities each give us important information about current uses of the internet, for the sake of a unified social justice principle it is necessary to interpret these forms of knowledge in terms of what could be. Marx's formula 'the development of each as a condition for the development of all' is put forward as the principle of a socially-just internet actualized from the ground up. It is argued that the most rapidly emerging and important form of constraint upon 'the development of each' is the for profit online social media industry in which moments of human communicative creativity become packaged as commodities for commercial purposes. Creative, cultural agency becomes an imposition rather than a liberation as represented in the industry ideology. It is argued therefore that groups that use the internet for serious play - the use of avatars in virtual worlds is discussed as an example - present us with a form of online subjectivity that is rising in importance as a form of cultural agency inasmuch as the play component is premised upon the rejection of pre-packaged forms of agency. Support for a socially-just internet would thus mean supporting the online communities formed in this process. Thus the argument is put forward that the importance of serious online play groups is not due to their potential for forming communities per se but is rather due to their potential for resisting the imposition of agency. Inasmuch as online communities in the midst of such groups can bolster that goal, they can represent the development of human capabilities in a way that expands the theme of social justice.
\end{abstract}

How can we incorporate the goals of peace and social justice into the theory and research methods of someone who is interested in the critical cultural analysis of the internet? I would begin by reminding us of an old, seminal principle. Despite all the events that have intervened in the last one hundred and fifty years, and the histories that have cast alternating favorable and unfavorable lights on this foundational document for socialism and communism, one of its core principles remains, at the very least an unavoidable issue:

In place of the old bourgeois society, with its classes and class antagonisms, we shall have an association, in which the free development of each is the condition for the free development of all (Marx \& Engels, 1948, p. 31).

The principle embedded here, I think, is that claims of social justice only make sense if they have some kind of universal relevance in human affairs. I once made an interesting discovery, however, about this particular quote when I was teaching the Communist Manifesto to students 
in a sociological theory class. I stated the quote in question from memory as 'the free development of all is the condition for the free development of each', and rather quickly a sharp student pointed out that I had gotten it backwards, implying that my error distorted its meaning. She was quite right: substituting 'each' and 'all' for each other in the phrase really does change the meaning, and the more I have reflected on this difference, the more I have wanted to write about it. Essentially, this little experiment in practical logic highlights the term 'the condition' and makes one realize how important this term is and how, I have come to believe, Marx's principle should be interpreted. The question is not: what are the conditions, involving all of us, that would permit the building of a socially-just world that would, in principle, benefit each of us? Rather, the question is: what are the conditions, involving each of us, that would permit the building of a socially-just world that would, in principle, benefit all?

Marx's condition for social justice raises an uncannily contemporary bottom-up, not top-down, vision of the future. This new interpretation was obscured from my view in previous readings, I now think, because I had assumed that Marx's laundry list of socialist reforms (abolishing private property; extension of factories owned by the state; obliging everyone to work; and so on) had to first be in place before any actor could hope to have an impact. Hence my pessimism. Now I see that if we take the idea seriously that 'the conditions' are such that they have to, from the very beginning, involve 'each of us' (as distinct from the more abstract notion of 'all of us'), it still involves a lot of people but it now means that there can be, and we ought to learn ways to recognize and appreciate, different speeds and different contexts, different ideas and different acts, in the world of those that are seeking to promote social justice. There is, indeed, room to think of our internet tools in a new way.

I used to do little more than fret over the monopoly of corporations like Microsoft over the possible ways we can think and communicate, and I still do not like that form of proprietary control over software, but now I am beginning to understand it in a different light. First IBM, then Microsoft, and now the new web 2.0 companies, have all along been trying to provide 'social utility software', as the chairman of Facebook likes to put it (Johnson, 2007). They are commodifying social relationships, ideologically promoting but in practice distorting and stunting the 'free development of each'. This is typically characterized by the aggressive extension of regimes of surveillance to the context of consumerism (Andrejevic, 2002). The interactivity of communication on the internet is further exploited by blurring the line between consumers and producers in order to extract labour from our most ordinary ways of interacting. A typical context for this exploitation is the 'start-up' company; the process of individuals, small groups and companies taking risks to introduce innovations in personal computing and networking technology has for some time now been slotted into a narrative of capitalism. The ideal hero of this narrative is the freewheeling, innovative individual or group willing to translate their life lessons into marketable products. These entities are seen as existing for the purpose of finding ways to profit from the fragile communities, unstable habits, and even the anti-corporate sentiments of internet users. An interesting example well advanced on this curve is Common Craft, a website devoted to producing videos that 'explain' various topics to 'ordinary people'. Common Craft cultivates a folksy, populist, left-leaning image. Based in Seattle, in the early 2000s its founders were inspired by the Cluetrain Manifesto (www.cluetrain.com). On its home page this document/website sets out its basic premise that "learning to speak in a human voice is not some trick, nor will corporations convince us they are human with lip service about 'listening to customers.' They will only sound human when they empower real human beings to speak on 
their behalf" (www.cluetrain.com). Common Craft has accordingly fashioned for itself not just an ideology of the corporate voice become more human, but an ideology of the ordinary person as 'owner' of the process of the production of value. ${ }^{1}$ Ostensibly to render the knowledge industry more grass-roots and democratic this conception places an accountability upon each person/producer that turns the collective components of their identities and needs into market engines to be exploited for enterprise and profit. The free development of each is distorted and stunted by a form of creative 'ownership' which is merely a pretense for the process of harvesting of workers' productive capacities.

The false ideology of the sovereign autonomy of the individual internet user, whether as producer or consumer, is all too often the organizational principle backing the 'social opportunities' of the internet which act as the fuel for these myriad engines of the capture of human creativity and communication. In this context, the notion of the internet as affording opportunities for 'the free development of all' has been far from helpful. Arguably, it has only disarmed and placated those who are attracted to these voluntary online sweatshops. If it is to make sense, the 'free development of each' (at least in my view of the significance of Marx's formula) cannot not be reduced to the mere notion that each actor should be able to live in a society structured to provide opportunities for their development. This is because it is only possible to imagine such a state of affairs if we conflate the principle of the 'free development of each' with a state of affairs that we imagine as the 'free development of all'. The rhetoric of helping humanity figures large in the self-justification of proponents of Common Craft and other start-ups in the social media sector. The capture of workers' creativity is presented as the realization of this social imaginary. The contemporary popular notion of an 'open source' movement (see, for instance, www.opensource.org) feeds this wishful expectation. But such notions all too often merely function to allow companies like Apple to outsource their problems at their leisure, stringing along contract developers who can't wait to serve them (VaughanNichols, 2006). Precisely by using the term 'is the condition of' Marx meant to avoid, not encourage, the conflation of his terms. It makes sense that he would do so, for it is regrettable when the principle of the 'free development of each' turns into an abstract ideology that merely enables a new kind of voluntary servitude. There is no commitment to social justice there. I for one at least, would favor any interpretation that maintained the actuality, the here and now, of 'the free development of each'. What I take from Marx is that all is lost if we do not create that condition.

What would it take to create the condition of 'the free development of each'? Certainly we would not know in advance what the outcome would be, though we would want to set out some goals, and we would want to examine our tools that we think we can use to promote those goals to make sure those tools do not have an in-built bias towards a limited consensus revolving around a pre-conceived conception of the 'all'. As John Stuart Mill put it, 'better to be Socrates dissatisfied than a fool satisfied' (2002, p. 397). Our goals will of course have to be constantly adjusted as different problems of social injustice and different aspects of those problems are identified, and there is probably a set of criteria that underpin the term 'social' in the term social justice, so we need to examine, as a matter of urgency, what that list would be and why their being 'social' is so central for human development. At the same time, though, we need to

\footnotetext{
${ }^{1}$ Own It | Common Craft - Explanations In Plain English. Retrieved October 16, 2008, from http://www.commoncraft.com/own-it\#comment-form.
} 
examine our tools. If you support the top-down perspective, any tools can be used to create the 'all' to 'manufacture consent,' as Herman and Chomsky put it (Herman \& Chomsky, 2002). If the job is to build social justice from the ground up, to attain first of all the free development of each, then tools must be fashioned or appropriated in a way that allows the user to create something unique to him or her.

This is the double problem, and the double solution, we have with the internet at the present moment of history. We are encouraged to set goals for peace and social justice because we can, but these calls are often irresponsible and not followed through. We seem to have the tools to communicate this message. But 'the message' slides into an abstract sense of the globalization of communication. The tools are skewed in favour of the development of an abstract concept of the all and do not permit the actual development of each. We have placed a principle of globalization as our highest value and then assumed that education, for example, would trickle down to the grassroots. It's the classic administrator's dream, like that of urban planner Robert Moses to transform New York into an expressway world for the benefit of 'all', at the expense of real neighborhoods and the actual practices of people (Berman, 1988). We should work to prevent the internet from being conceived as another expressway world. For me this is exactly why the critical cultural and social study of the internet is so important today.

The perspective of critical cybercultural studies examines the internet as a potential space of social justice and democratic politics for users who are already engaged with computer-mediated communications. It is a valuable perspective that is generating new data and insights every day. We also need to engage with studies of the digital divide, of course, to understand the disparities in the current global systems. These studies inform us of current actualities. We need to go further though, and look at this information from the point of view of 'what could be'. We need to reclaim the utopian ground that is being appropriated by Google Earth, MySpace and Windows Live Messenger. My point of view, as I have tried to justify above, stresses an interpretation of current actualities to the extent that they are already actualizing 'the development of each', or providing obstacles thereto, as the condition of understanding and promoting social justice. However, I am also proposing to effect this interpretation without reducing this condition to mere abstract notions of individualistic liberty, since the key criteria of social justice is, after all, that it is a social and cultural construction. Essentially, then, I am interested in a discussion that bridges the gap between 'what is and what could be' in internet practices and research, from an over-arching social justice point of view which stresses the 'ground up' actualization of social justice. A discussion, then, needs to take place that bridges structural and ethnographic analysis of internet practices from the standpoint of a normative, processual conception of social justice.

To achieve a satisfactory depth of understanding one would have to examine the problems that have historically divided ethnographers and structural theorists and the many solutions that have been proposed as ways of synthesizing micro and macro, structure and agency theoretical orientations. Here I am going to limit myself to pointing out a problem with the present state of internet research that gets in the way of this undertaking. This problem consists in the assumptions of researchers and theorists about 'what could be', or about an ideal social justice outcome. For the sake of simplicity of argument let me for the time being reduce the approaches to digital divide (structural) vs. cybercultural (ethnographic) points of view. I am going to interrogate these positions on what they assume 'could be', and examine their implications for research that is motivated by the problems of social injustice. My ultimate aim is to ask: how can 
the goals of peace and social justice be incorporated into the theory and research methods of someone who is interested in the critical cultural analysis of the internet?

The most well-developed approaches to online social justice to date have been those dealing with the problem of the digital divide. The digital divide encompasses all the social stratifications, political conflicts, economic inequalities, and infrastructural developmental delays that have prevented the internet from reaching vast numbers of users. ${ }^{2}$ The proponents of the digital divide perspective generally assume that members of different societies and cultures around the world need or want to be users of the internet. This kind of assumption is fair in social science research that examines structures that prolong inequality and injustice in the traditional, offline world. It is fair to assume that members of societies would need or want access to all the goods of societies that are rightfully theirs. It is fair in that context because the actors in the traditional, offline world have no choice but to be and act in that world. In contrast, imagine a group of actors who came together and created a space for themselves in which they built an environment, which they could use from time to time, in which they expected to avoid harming each other but the main positive expectation was that social interactions therein would experiment with communication and usually involve some kind of creative expression. Let us call them the serious play group. Let us assume, for the sake of argument, all the members of the serious play group agreed with these expectations and faithfully tried to stick to their spirit for the time they were within that space. They could use the space for any kind of expressions or learning, to dramatize and learn about any kinds of real world conflicts or cultures. These are highly motivated participants in a social group, and they have chosen to enter their group's space. What we should note is that this would not be for everyone. Not every actor would choose to be, or even know that they could be, involved in such a group. Not every actor in today's world chooses to use the internet as a means to address their needs and wants. Moreover, significant groups of users have entirely different schemas that guide their online practices. ${ }^{3}$

The notion of a serious play group highlights a form of agency, along with attendant cultural schemas, tactics, and strategies of action that is very specific to online computer-mediated communication. One way to draw the contrast with the agency that the digital divide perspective generally deals with is to note how the latter perspective has its strength in illuminating problems of institutions and social interactions represented online which operate in the context of current trends towards globalization and networked individualism (Wellman, 2002; Hackworth, 2007). New social networks are enabled by computer-mediated communication. They are creations of actors who are highly selective as to with whom and where they associate. They form new kinds of communities with non-traditional spatial formations (Wellman, 2002). The flipside is the mass of people who lack these means of selective association and spatial control, and hence lack increasingly important means of social, economic, and cultural capital. A key point to remember is that this whole problem of social transformation and accessibility to networked communities

\footnotetext{
${ }^{2}$ Norris has developed an interesting way of understanding this with the concept of information poverty (Norris 2001).

${ }^{3}$ I would add the caveat that if government agencies, corporations, employers, or other global institutions were to come along and disrupt groups like the serious play group, undermining the 'play' aspect by creating conditions whereby offline social functions can only be accomplished on the internet, under these circumstances the digital divide perspective grows in relevance.
} 
by social networking cannot be accurately described in terms of group dynamics since it operates according to a logic of interest-driven contextual embedding and disembedding. If I see myself as a member of a community of Lexus owners, I am going to jump across various socio-cultural, geographical, economic, and political contexts in order to interact in networks of like-minded others. In contrast, a group is an assembly of actors who do not need to be more than incidentally interested in each other. Wellman sees a fundamental intransigence in the sociological conception of group that gets in the way of seeing the new realities of social networking (2002).

I would see the concept of group as quite important as a means of describing some social assemblages such as those meant for serious play. I agree that groups are not necessarily, or even usually, communities. I would suggest we define a group as an event of assembly. The point I want to make here is if serious play groups are groups as such then the digital divide problem is not well set up to account for their formation. A serious play group is an event of assembly meant to explore creativity with communication and therefore cannot be defined as a social network or a community since the latter depend on communication taking defined, functional, and relatively stable forms. A serious play group defined from the perspective of a social network or community would appear as dysfunctional, and we would get the wrong idea about it. The members of the serious play group - let us say they are well-off westerners though they do not have to be - could certainly be said to be responsible for helping to solve the problem of the digital divide, but I would hold this to be true only qua members of their broader societies, not qua members of the serious play group. This in no way diminishes the intensity of the responsibility of those actors, of course, it just clarifies its source, and it permits us to appreciate the autonomy of the serious play group, and to explore what the latter could be a source for instead.

I am concerned that the digital divide may very well entrench people's thinking about the internet in terms of generalizations relating to the power relations involved in actual institutional appropriations of the net. It is all too easy to rely on some vague narrative about the spread of the internet as some kind of abstract impersonal force like what Weber called rationalization, an inevitable outcome of 'our western logos', leading to an inexorably widening institutional iron cage that traps us all into employing its ways of thinking, being and acting. In actuality, the internet's history has always been related to large powerful institutions, but also to serious play groups (Turner, 2005). When we want to think of where the internet came from and 'what it could be', the digital divide perspective has no answers and instead we need ethnographic research in order to understand the actual use of the computer-mediated communication on the net and the directions implied by this actual use. It is a crime if actors are prevented from participating online because they do not understand the internet and are worried about how glocal and impersonal and conspiratorial it feels. It is sad if people think that all they can do as individuals is to click on a few preferences and banners set up well in advance by big companies. The digital divide perspective just does not have its strength in helping us to know what could be, with respect to the social justice dimensions of the net. It is unlikely that the net would resemble its present incarnation if it really was adopted even by a clear majority of the world's populations. We cannot, and should not rest our understanding of the internet on information about 'what is' the case with respect to unjust distribution of access at the present moment. We should use that information to work toward a more equal distribution, for those that need or want the internet. We do not waste our time fighting to distribute prosthetic limbs to every person on the planet, but only those that need or have a good case for wanting one, and we want to make 
sure that we understand how the technology is going to be used. Working towards a better understanding of the use of the net by serious play groups will at least enable us to gain a clearer conception of a form of online subjectivity that is not based on narrow interests.

The proponents of a critical cyberculture are well positioned for this task. They have a valuable perspective, to begin with, because they are able to avoid the problematic assumption that everyone desires to be an internet user. ${ }^{4}$ An anthropologist studying an aboriginal tribe in Australia can accomplish a great deal without in any way presuming that the ways of life of that tribe should be adopted by all human beings. This is because the main task of the anthropologist is the thick description of a culture, and their indifference to the interests of the rest of the world is actually a source of the objectivity of the anthropological, or in the case of the internet, the ethnographic voice. However, that does not mean there are not circumstances in which one might want to ask if certain specific cultures can be adopted more widely, to bring some wisdom to the world, and what the consequences of this might be. One also, of course, should at some point ask the question of development, of whether certain specific cultures have taken on their specific cultural features because they have been isolated from the world and its vaster resources, and to what extent and under what circumstances calls for the importation of western ways and means should be encouraged. It should be obvious that many social justice scholars and activists who do excellent and worthy work are involved precisely in these questions and in seeking culturallysensitive modes of the recognition of problems and identities, and of the distribution and delivery of basic resources. Here I am just pointing out that such questions go well beyond what a traditional ethnographer will tend to deal with. The proponents of a critical cyberculture, as ethnographers, avoid the uncritical universalization of the subjectivity of internet, but are not equipped to analyze the digital divide. They have to work on the assumption that their methods are permitting them to accurately critically analyze what the internet and its actual usage in the social context is.

But there is a more unique problem that only ethnographers of the internet have to face on a daily basis. The problem is not the heavy involvement of technology per se, since technologies have always come into the equation in traditional, offline communities. The problem is the norm of creative collaboration among internet users, particularly in the serious play type of use. Ethnographers of traditional, offline communities can practice thick description and social justice activists can work for the development of those communities, and they will debate among themselves, as they ought to, about the consequences of intervention in a culture to distribute aid or promote education and the nature of the impact on various subjectivities and their identities. However, they prosecute this debate on the shared common understanding that the members of those communities are more or less committed involuntarily to their communities. They do not have to deal, primarily and on a daily basis, with subjects who have a voluntary, experimental relationship with their communities based on its potential for collaborative creative expression. At the same time, within internet research, there is a curious parallel between the digital dividers and the ethnographers insofar as they both tend not to explore whether a wider social usage of the net would alter its functions. In the scholarly mode that they have to employ, they both tend to discuss how the net 'is' rather than what it 'could be'. In contrast, in the actual practices of

\footnotetext{
${ }^{4}$ Some notable internet ethnographic studies include the pioneer studies of Howard Rheingold (1993) and Sherry Turkle (1995), and many more recent studies, including Baym (1998); Markham (1998); Danet (2001); Howard and Jones (2004).
} 
those who use the net, among bloggers for example, the norm is to constantly tease out the implications of all practices to make sure they fit the future. ${ }^{5}$

The condition of online social justice would have to be a universal perspective, and not primarily in the sense of the theorist's perspective of looking down upon a great digital divide. This universal perspective must somehow be embedded in the plurality of online activities, including organizations and practices. ${ }^{6}$ The phenomenon of serious play groups voluntarily using the internet for their own purposes is a significant form of internet activity which has played an important role at the beginning and continuously during the historical evolution of the net, and has always displayed an inherent resistance to corporate co-optation of online activities. To be sure, we will only fully understand the significance of serious play groups if we support the advancement of internet ethnography. But in the meantime the question becomes: in what sense might the voluntary nature of serious play groups using the internet constitute the kind of plural yet universal perspective we are looking for? Might serious play groups be a source of inspiration for the advancement of online social justice?

While we need to continue to research the social structures and ethnography of the internet, if these projects are to be steered in a way that renders them mutually supportive of social justice activism, one of the greatest tasks that lies ahead is the theoretical enterprise of critically examining the possible social justifications of promising internet activities. It is an enterprise of seeking common ground, and it is also becoming more and more urgently a critical enterprise as corporations have been moving faster to promote certain 'social software' concepts of the internet than social theorists and social justice activists. For the companies promoting their products, a key problem is understanding how technical innovation allowing for greater flexibility and usability can be translated and promoted as a kind of agency, or expansion of the agency of the human user. Take for example the 'avatars' that users employ in order to interact in virtual worlds like Second Life (secondlife.com). In the technical design of systems that support avatars, it is a vital question of concern to social software developers to determine how an avatar can be deliberately designed to be technically flexible in terms of the contents of its identity. Social software developers in general want to play, of course, to their companies' desires to promote mass personalization (Miceli, Ricotta, \& Costabile, 2007). Attentions are much less focused, if at all, on the cultural dimension in which this flexibility comes to be, in actual practices, manifested as cyberplay that expresses the peculiar self-understandings, stories and symbols that come to be grouped around the identities of avatars and the online communities they inhabit. A central question for theorists addressing social injustice has been the problem of how to defend and implement human rights. The online context, in which humans use avatars which in turn expand human reality to a new level of sociable interaction and serious creative play, complicates this question, requiring that we explore the human meanings of avatars in relation to the meanings generated in avatar-to-avatar interactions.

We must not dismiss the small but significant plurality of ways inhabitants of virtual worlds and participants in all kinds of online communities are using these tools every day, since very often their methods were not intended or conceived by their primary developers. Serious cyberplay is play with the form of communication in the online context, and outcomes of play are impossible to predict. Play inherently resists the imposition of agency. It does connect with

\footnotetext{
${ }^{5}$ See for example http://lifehacker.com/

${ }^{6}$ The New Media Consortium (www.nmc.org) is notable for encouraging excellent work in this spirit.
} 
the more mundane issues surrounding the internet. Resistance to corporate attempts to impose agency functions in the context of concerns over who can and should have access to technology. The recent rapid expansion of virtual worlds for children is a case in point. It is the rare family now who does not have a child using her avatar (the 3D graphic characters that move about in virtual worlds) to make points and build an online presence in sites like Club Penguin or Stardoll. These sites seriously discipline and channel the agency of child actor-avatars. This is ostensibly due to their users' tender ages, but the Disney executives who run Club Penguin will tell their boards that it is to train new consumers to accept their digital products.

The appropriate institutions for the inculcation of good online habits in children, such as families and schools, are facing a cultural and ethical struggle which depends, like all social justice movements, upon participation and community. Some social justice thinkers who have thought deeply about computer technology continue to be informed by the traditional view that 'if anything, technology aids in the reduction of the other into an object or means' (Walters, 2001 , p. 22). However, at the same time it is recognized that 'community protects and fulfils rights' (Walters, 2001, p. 22). Thus, the question of whether the virtual world can be a space of social justice is naturally understood, as a kind of default approach, as a question of whether it constitutes a real, effective community. Ethnographers of the internet have worked diligently to prove that such communities can exist, albeit often in a fragile way (Baym, 1998). However, the problematic of community needs to be re-shaped as we gain more accurate ethnographic information about serious play groups.

To begin with, there are important differences between online and offline communities. Online communities tend to be oriented to play. Let us take, for example, the use of avatars in virtual worlds like Second Life, an area in which I am presently developing a long term ethnographic research project. ${ }^{7}$ One of the debates that I have had with my internet research colleagues surrounds the ontological status and agency of avatars. ${ }^{8}$ We have debated, for example, the analogy between avatars and puppets. Like avatars, puppets are controlled by puppeteers, and can thus be considered within the world of the direct representations of the puppeteer. Employing the model of the puppet/puppeteer relationship, the ethical considerations of avatarto-avatar interactions in Second Life would be similar those in studying offline interactions. Puppets interact with other puppets. They do so as expressions of their puppeteers' intentions, or as vehicles of the puppeteers and/or audience's symbolic interpretations of those (on stage) interactions. Thus, one could well argue that a dramaturgical theoretical framework, like that proposed by Goffman (1973), would be an interesting way of studying Second Life interactions.

Traditional social interactionist theories work well in studying traditional offline social interactions, are time tested, and are a useful theoretical starting point. However, problems crop up in the online context. One finds, in practice, a significant disanalogy between avatars and puppets. Second Life avatar interaction is not like a puppet show because it is not a 'show' in the sense of a definite dramatic performance with a beginning, middle, and ending and a set of actors that are guided by a director. In Second Life there is no director. There is an orientation process

\footnotetext{
${ }^{7}$ I acted as principal investigator in a pilot study that took place in 2007, 'The Impact of Communicative Creativity on Human Needs and Social Justice', Humanities and Social Sciences Research Grant (HSSRG), University of Windsor, Ontario, Canada, 2007.

${ }^{8}$ These discussions have taken place in March of 2008 on the listserver of the Association of Internet Researchers (AoIR).
} 
in which one learns the movements and communication functions of one's avatar, but once the basics are learned, the individual subscriber is left completely to his or her devices, to go and join or form groups for business, pleasure, education, or whatever. To use the language of the social psychology of George Herbert Mead (1967), this means that one avatar has to respond to the other avatar according to the way the first avatar's human user imagines is the attitude, not of the second avatar's human user, but of the second avatar, since there is no way to check the attitudes of the human user without disrupting the immersive quality of the virtual world. Analogous to the need for concentration and immersion in a game as a condition of getting the most out of a game, immersion in Second Life is the whole point for the vast majority of its users. ${ }^{9}$ Adding to the difference from human-to-human interaction in the offline world, in Second Life avatars, of course, compared to humans have a different repertoire of possible movements and expressions with different in-built limitations (e.g. Second Life avatars can fly and teleport). So the human user of an avatar has to interpret the meaning of the other avatar's actions without being able to check the attitudes of the human user (or at least with an in-built discouragement in the world from doing so and a drastically-reduced ability to do so) in a context that is qualitatively different than a human context. And all of this takes place in an environment in which it is quite possible for an avatar to be harmed by another avatar. The capabilities of one avatar can be impaired by that of another, quite independently of the relative states of the human users.

Creativity and experimentation - serious cyberplay - is arguably the norm online, and avatarbased virtual worlds give a glimpse into where this world is heading. The quality of one's experience in Second Life depends on a distinct set of norms and values of its user community, and injustices within the virtual world can and do occur. All communities, whether online or offline serve a variety of functions of social integration and social regulation. A serious play group is not the same as a community. But when an actor in a group is recognized by a community they are then able to legitimately struggle for their right to the kind of life experiences they expect, and the capability to pursue them. In the online context, in which creativity is an over-arching norm, the serious play groups have need for community in order to support a struggle for a key primary right: the right to develop one's online technical and social capabilities. Thus, groups, including serious play groups, depend on communities to nurture and protect the new conceptions of social justice they might develop. For other kinds of rights, of course it is appropriate and necessary for human beings to fall back on offline communities for recognition and support. But this new kind of right has emerged: the right to be able to develop one's abilities online. 'Wilde Cunningham' is an actor-avatar and resident of Second Life. He is the creation of nine disabled people, who control their avatar by democratic vote and the help of their caregiver. In traditional computer-mediated formats, the standard unit of analysis is the 'computer user'. This is a thin description that does not capture the complexity of the actoravatar, as they are an in-world invention of individuals and groups. A key consequence of the radically different forms of social interaction that avatars enable is that they pose a theoretical problem for understanding the nature of sociability and unsociability in the virtual context. From

\footnotetext{
${ }^{9}$ Of course, however, Second Life is not a 'game' since there is a plurality of activities of all different kinds with no general object and no quest. One must differentiate the non-gaming nature of Second Life with virtual online gaming worlds like World of Warcraft.
} 
an outsider's point of view actors heavily involved in virtual worlds often appear unsociable due to the technical knowledge involved, a tendency towards technical elitism, a preoccupation with constant innovation, and fears of internet addiction. Indeed, among those attracted by the numbers of subscribers to Second Life and to the idea of establishing a regular presence in-world - including individuals and private and public institutions - there have been concerns raised over a perceived inconstancy, fragility, and shallowness of participation levels in the virtual environments. The actors that operate avatars like Wilde, however, believe Second Life permits them to sidestep stigmas and release creative and collaborative energies. In Second Life, users have gone beyond mere entertainment and utilitarian uses of communication, raising hopes for expanding the possibilities of human reality through their serious cyberplay.

In the future, those struggling for rights-based social justice will have to recognize the centrality of these processes of virtual social reality in no less an urgent way than past societies based on print media communication espoused freedom of conscience. Being free to develop each individual or group actor's abilities online means being free from obstacles to creativity, being free, for example to alter the source code for the software one employs for communication. Martha Nussbaum argues that social justice is a situation in which human capabilities are maximized (Nussbaum, 2006). Nussbaum's theory of human capabilities as the object of social justice develops a sense of the need of the engaged actor to be involved in activities in order to flourish. Similarly, online capabilities, in which creativity is the foremost value, are not static assets or rights to be 'accessed', or passive 'liberties', but are a socially-needed, dynamic and constituent part of the socially-constructed identities of online actors.

I have presented the digital divide perspective and the cybercultural perspective as structural and ethnographic traditions of internet research that are useful, though inherently limited, sources of documentary information about how the net is used. This is admittedly an over-simplification of the varieties of internet research, but my task here was not to outline this rich variety. The point I have wanted to stress in this paper is that online social justice depends on internet practitioners making a qualitative leap by actually performing social interactions that necessarily involve a more urgent question of 'what could be' in terms of the 'free development of each'. The maximization of human capabilities, a promising theory, in the context of the net surely depends on strengthening online communities and encouraging the separation of corporate control and serious play on the internet. We also need to remember and be aware of the social structures that bind the offline and online worlds into a broader society which does break down into unfortunate stratifications that prevent equal access to technology. Working towards internet social justice partly involves this broader social struggle. However, our struggles should be informed and guided, not by a negative sentiment of 'well, if these are the paltry tools that are imposed on us today, at least I want my fair share of access to those tools'. Rather, we should take on a cognizance of the peculiar necessities of online interactions by recognizing, appreciating, and critically-scrutinizing the experience, norms, and values of communities who are actually in the process of developing and practicing what the net 'could be'. It is not just a case of understanding the serious play structuring the intensely sociable culture of online interaction better by supporting the advancement of internet ethnography, though the latter is important. What is crucial is seeking a basis for understanding the complexities of social justice in the virtual community. Let us be critical, wary agents concerned to defend the gains and wellbeing of our broader societies, but let us be open to what virtual community actors are showing us 'could be' - the free development of each as a condition for the free development of all. 


\section{References}

Andrejevic, M. (2002). The Kinder, Gentler Gaze of Big Brother: Reality TV in the Era of Digital Capitalism. New Media \& Society, 4 (2), 251-270.

Baym, N. (1998). The Emergence of Online Community. Cyber Society 2.0: Revisiting ComputerMediated Communication and Community. Thousand Oaks, CA: Sage.

Berman, M. (1988). All That Is Solid Melts into Air: The Experience of Modernity. New York, N.Y: Viking Penguin.

Danet, B. (2001).Cyberpl@y: Communicating Online. Oxford: Berg.

Goffman, E. (1973). The Presentation of Self in Everyday Life. New York: The Overlook Press.

Hackworth, J. R. (2007). The Neoliberal City: Governance, Ideology, and Development in American Urbanism. Ithaca: Cornell University Press.

Herman, E. S. \& Chomsky, N. (2002). Manufacturing Consent: The Political Economy of the Mass Media. New York: Pantheon Books.

Howard, P. N. \& Jones. S. (Eds.) (1998). Society Online: The Internet in Context. Thousand Oaks, Sage

Johnson, B. (2007). Web 2.0 Summit. In M. Zuckerberg (ed.), Facebook Technology. Retrieved on March 14, 2008 from:

http://blogs.guardian.co.uk/technology/2007/10/17/web_20_summit_mark_zuckerberg_facebook.html

Markham, A. (1998). Life Online: Researching Real Experience in Virtual Space. Walnut Creek, CA: Atlantic Press/Sage.

Marx, K. \& Engels, F. (1948). Manifesto of the Communist Party. New York, N.Y: International Publishers.

Mead, G. H. (1967). Mind, Self, and Society from the Standpoint of a Social Behaviorist. Chicago: University of Chicago Press.

Miceli, G. N., Ricotta F. \& Costabile, M. (2007). Customizing Customization: A Conceptual Framework for Interactive Personalization. Journal of Interactive Marketing, 21(2), 6-25.

Mill, J. S. (2002). Utilitarianism. In S. Stumpf \& D. C. Abel (eds.), Elements of Philosophy (pp. 394-400). New York: McGraw-Hill.

Nussbaum, M. C. (2006). Frontiers of Justice: Disability, Nationality, Species Membership. Cambridge, Mass: The Belknap Press.

Rheingold, H. (1993). The Virtual Community. Reading, MA: Addison Wesley.

Turkle, S. (1995). Life on the Screen: Identity in the Age of the Internet. New York: Simon and Schuster.

Turner, F. (2005). Where the Counterculture Met the New Economy: The Well and the Origins of Virtual Community. Technology and Culture, 46, 485-512.

Vaughan-Nichols, S. (2006). Open Darwin Shuts its Doors. Linux-Watch. Retrieved on March 14, 2008 from http://www.linux-watch.com/news/NS

Walters, G. J. (2001). Human Rights in an Information Age. Toronto: University of Toronto Press.

Wellman, B. (2002). Little Boxes, Globalization, and Networked Individualism. In M. Tanabe, P. Besselaar \& T. Ishida (eds.), Digital Cities II (pp. 11-25). Berlin: Springer-Verlag. 